\title{
Géolinguistique
}

$16 \mid 2016$

Varia

\section{Torres, castelos e castros no mapa linguístico de Portugal Continental}

" Torres », "Castelos » et « Castros » sur la carte linguistique du Portugal continental

"Torres", "Castelos" and "Castros" on the Linguistic Map of Mainland Portugal

\section{Luís Salema}

\section{(2) OpenEdition}

12 Journals

\section{Edição electrónica}

URL: http://journals.openedition.org/geolinguistique/570

DOI: 10.4000/geolinguistique.570

ISSN: 2650-8176

\section{Editora}

UGA Éditions/Université Grenoble Alpes

\section{Edição impressa}

Data de publição: 1 dezembro 2016

Paginação: 225-252

ISBN: 978-2-84310-342-1

ISSN: 0761-9081

\section{Refêrencia eletrónica}

Luís Salema, «Torres, castelos e castros no mapa linguístico de Portugal Continental », Géolinguistique [En ligne], 16 | 2016, mis en ligne le 15 février 2019, consulté le 30 octobre 2020. URL : http:// journals.openedition.org/geolinguistique/570; DOI : https://doi.org/10.4000/geolinguistique.570 


\title{
Torres, castelos e castros no mapa linguístico de Portugal Continental
}

\author{
Luís Salema \\ Universidade d'Aveiro, \\ Centro de Línguas, Literaturas e Culturas
}

\section{Résumé}

Dans cet article, nous présentons une étude sur quelques toponymes du Portugal basée sur le mot «Castelo» (château), «Castro» (fortification pré-romaine) et "Torre» (tour). Nous avons fait l'analyse des noms de lieux du point de vue morphologique et syntaxique. L'analyse a identifié trois groupes principaux, en tenant compte des structures morphiques qui se produisent : 1) les noms de lieux avec un nom simple; 2) les noms de lieux avec des variations de classe, de degré ou avec un suffixe dérivationnel; 3) composés syntagmatiques, avec ou sans éléments de connexion, dont la structure est la plus productive et celle qui présente plus de variation dans les processus de composition. Dans ces composés, la définition du noyau du syntagme toponymique peut être problématique et semble être basée sur des critères pragmatiques et culturels.

\section{Mots-clés}

Formation des mots, noms composés, toponymes.

\section{Abstract}

In this working paper, we discuss the toponyms of Portugal, based on the words "Castelo" (castle), "Castro" (fort) and "Torre" (tower). We analyzed the place names from a morphological and syntactical approach. The analysis identified three major groups, according to the occurring morphic structures: 1) place names with the simple name; 2) place names 
with grade, gender and number variations or derivational suffixes; 3) compound nominal groups, with or without connective elements, which structure has proved to be more productive and with more variation in compositional processes. In these compounds, nucleus definition can be problematic, seemingly based on pragmatic and cultural criteria.

\section{Keywords}

Words formation, compound nominal groups, toponyms.

\section{Resumo}

O artigo lança um olhar sobre os topónimos de Portugal Continental, assente nas palavras «Castelo», «Castro» e «Torre». Analisaram-se os topónimos do ponto de vista morfológico e sintático. A análise permitiu identificar três grandes grupos, tendo em conta as estruturas mórficas ocorrentes: 1) topónimos com o nome simples; 2) topónimos com variações em grau, género e número ou com sufixos derivacionais; 3) compostos sintagmáticos, com ou sem elementos conetivos, estrutura que se revelou mais produtiva e com maior variação nos processos compositivos. Nestes compostos, a definição do núcleo do sintagma toponímico pode ser problemática, parecendo assentar em critérios pragmáticos e culturais.

\section{Palavras-chave}

Formação de palavras, nomes compostos, topónimos.

\section{Introdução}

No verão de 2011, o jornal Público incluiu um conjunto de cinco artigos reunidos sob a epígrafe «Viagem pelo país surreal da toponímia». Nessas linhas, o jornalista Luís Francisco percorre o país, salientando particularidades da toponímia portuguesa, destacando, com mais ou menos humor, as designações dadas a alguns locais de Portugal Continental. Adotando uma perspetiva focada na extensão dos nomes, no seu caráter poético, na bizarra escolha dos vocábulos ou no léxico da gastronomia, viajamos do breve Ul (Oliveira de Azeméis; Aveiro) ao extenso Monte Santo António Chafariz d'El-Rei (Elvas, Portalegre). Passamos, depois, por Cega Gatos de Baixo (Viana do Alentejo, Évora) e Alto de Baixo (Monchique, Faro), avistamos Campo de Víboras (Vimioso, Bragança) e passamos ao lado de Cadela Morta (Cinfães, Viseu). Descansamos, depois, em Tapada das Águas de 
Verão (Nisa, Portalegre) e pensamos em nomes como Saramonheira de Cima (Grândola, Setúbal) ou Carne Assada (Sintra, Lisboa).

Aquando da recolha de corpora para trabalhos no âmbito do projeto AMPER - Atlas Multimédia Prosódico do Espaço Românico, da Universidade de Aveiro, enquanto se percorrem quilómetros para ir ao encontro dos informantes, as indicações toponímicas despertam, muitas vezes, o interesse de quem se debruça sobre as questões linguísticas. Assim, passa-se por Venda da Porca (Estremoz, Évora), Árgea (Torres Novas, Santarém) ou Estômbar (Lagoa, Faro).

As considerações de José Leite de Vasconcelos também ilustram esta topodiversidade. No segundo volume da Etnografia Portuguesa, o autor oferece-nos elementos importantes para compreender a toponímia usada em Portugal. Entre as principais linhas estruturantes do seu pensamento, acham-se as que se referem ao uso de topónimos que remetem para a agricultura (e.g. Mêda, Guarda), para a presença da água (e.g. Lagoa, Faro), das praias (Praia da Falésia, Albufeira, Faro) e dos animais (e.g. Raposeira, Vila do Bispo, Faro). Para além destas, são recorrentes as designações que remetem para a configuração do solo (e.g. Vale de Parra, Albufeira, Faro), para o clima (e.g. Mesão Frio, Vila Real), para a organização da sociedade (e.g. Albergaria-a-Velha, Aveiro) e para a existência de fortificações (e.g. Torre Velha, Ponte da Barca, Viana do Castelo; Viana do Castelo ou Castro Verde, Beja). As fortalezas, os castelos e outras construções similares foram de tal modo abundantes, sobretudo nos finais da Idade Média, que levaram Leite de Vasconcelos a considerar que:

Se fosse possível a um indivíduo, nos fins da idade-média, subir aos ares em aeroplano, e lançar de lá o olhar por sobre a nossa terra admirar-se-hia de que ela, apesar de pequena, estivesse coberta, em grande parte, por fortificações: e ao mesmo tempo folgaria acaso de contemplar as torres, que the davam, por assim dizer, o aspeto de florestas formadas de altos troncos de arvores, despidos de ramaria. (Vasconcelos, 1995 reimp: 591-592)

Este contacto com estudos de toponímia e, muitas vezes, com os próprios locais despertou o interesse pela temática e, consequentemente, a realização deste trabalho, centrado na dimensão linguística dos signos toponímicos. Dada a diversidade da temática, optou-se por considerar as afirmações de Leite de Vasconcelos, no que diz respeito à presença das designações de fortificações na construção de topónimos portugueses, pois, como se viu, na Idade Média, mas também ao longo de outras épocas, as construções militares acabaram por deixar uma marca importante, não só na paisagem física do nosso país, mas também na sua paisagem toponímica. 


\section{Objetivos do estudo}

Com este trabalho, pretende-se realizar um estudo linguístico dos signos toponímicos que incluem as palavras «Castelo», «Castro»e «Torre», partindo das questões que a seguir se enunciam:

1. De que forma se reflete a presença desses vocábulos na toponímia de Portugal Continental?

2. Quais os processos linguísticos utilizados na construção toponímica, recorrendo aos três itens lexicais selecionados?

3. Que processos linguísticos se revelam mais produtivos para a construção dos topónimos, com base nestas três palavras?

Neste estudo, privilegia-se uma abordagem centrada nos aspetos morfológicos, sintáticos e semânticos da construção dos signos toponímicos, tendo em vista a identificação dos processos linguísticos envolvidos na formação dos topónimos e fornecendo uma descrição dos elementos constituintes das suas estruturas. As considerações de caráter social, histórico e cultural assumem um papel subsidiário, no contexto deste estudo, procurando esclarecer e completar as bases linguísticas subjacentes à construção do topónimo.

\section{Metodologia}

A recolha do corpus assentou na consulta da base de dados Visitar Portugal - enciclopédia das localidades portuguesas, disponível em <www. visitarportugal.pt $>$. Esta base de dados permite selecionar, no mapa de Portugal, o distrito a pesquisar, aparecendo, depois, a lista de todos os concelhos que o constituem. De seguida, surgem elencados todos os topónimos desse concelho. Os diferentes níveis de pesquisa possibilitados pela base de dados selecionada são apresentados de seguida (fig. 1 e fig. 2):

Na pesquisa realizada, em cada um dos concelhos, consideraram-se todos os topónimos com os lexemas «Castelo», «Castro» e «Torre», na sua estrutura. Durante o processo de recolha, verificou-se que a estes termos eram adicionados sufixos flexionais de número, avaliativos ou derivacionais. Adicionam-se, igualmente, outros lexemas, originando produtos toponímicos com configurações variáveis. A existência destas variantes permitiu a constituição de subcorpora, com termos «secundários», cuja descrição constitui a linha estruturante deste trabalho. 


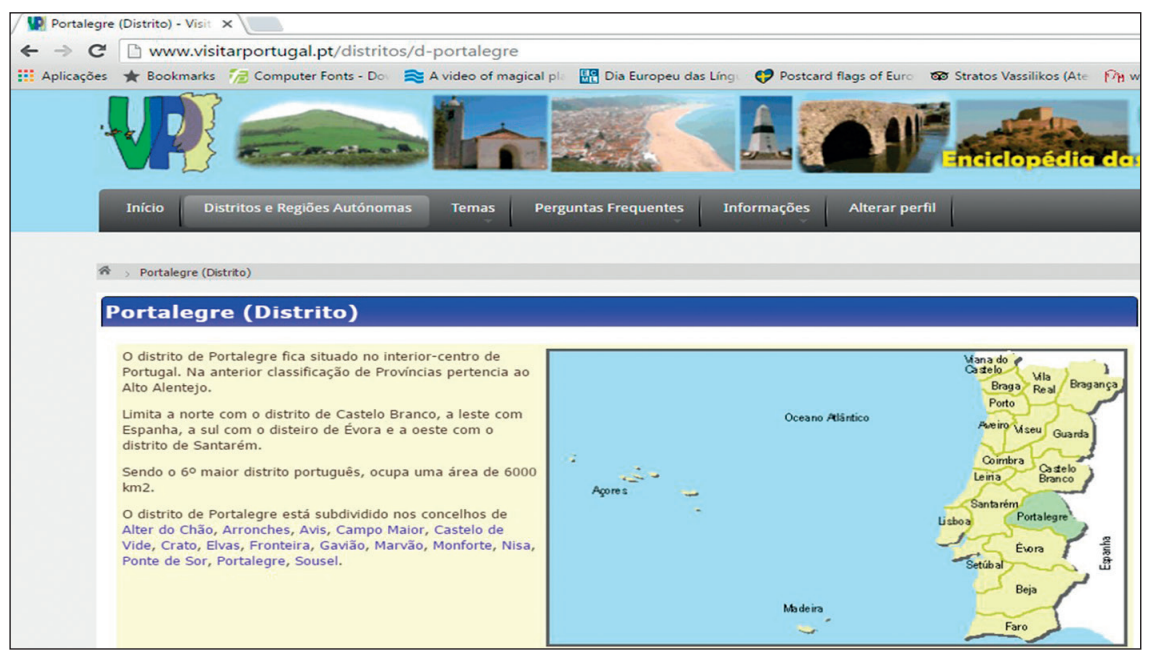

Figura 1. - Pesquisa de topónimos por distrito e por concelho.

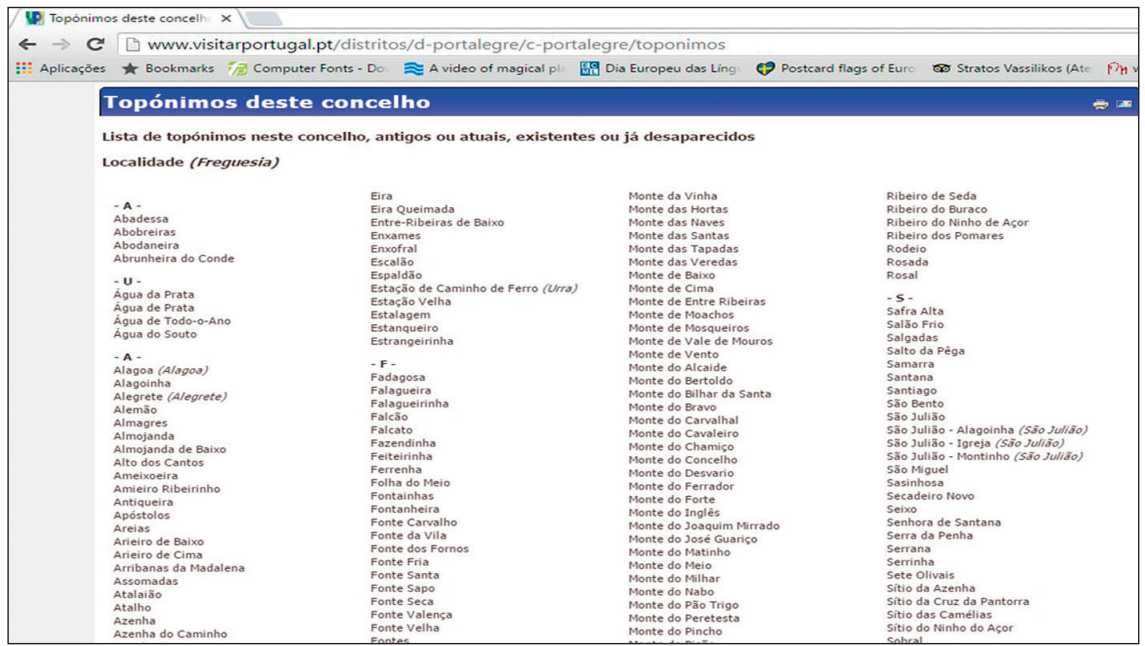

Figura 2. - Pesquisa de topónimos, para o concelho de Portalegre.

A constituição do corpus global e dos subcorpora dele derivados materializou-se na elaboração de tabelas, por distrito e por concelho, e na contagem das ocorrências das estruturas em análise, tendo sempre na base as três palavras selecionadas como ponto de partida para a pesquisa realizada. A essa base, foram associados termos «secundários», resultantes das variações flexionais e derivacionais e das expansões em torno das formas primárias, concretizadas em produtos composicionais de extensão variável. 
Elaboraram-se tabelas, para cada um dos distritos de Portugal Continental, com a indicação do concelho e dos topónimos existentes, de acordo com os critérios selecionados e com a contabilização do número de ocorrências, como a que a seguir se apresenta, para o distrito de Aveiro (tabl. 1):

\begin{tabular}{|l|l|l|l|}
\hline \multicolumn{1}{|c|}{ Aveiro } & Castelo (8) & Castro (1) & \multicolumn{1}{c|}{ Torre (8) } \\
\hline Águeda & & Castro de São Jorge & \\
\hline Albegaria-a-Velha & Castelo & & Torres \\
\hline Anadia & Póvoa do Castelo & & $\begin{array}{l}\text { Fragas da Torre } \\
\text { Quinta da Torre }\end{array}$ \\
\hline Arouca & & & \\
\hline Aveiro & & & \\
\hline Castelo de Paiva & Castelo de Paiva & & \\
\hline Espinho & & & Torre \\
\hline Estarreja & & & Quinta da Torre \\
\hline Santa Maria da Feira & Castelo & & Torre do Viso \\
\hline Ílhavo & & & \\
\hline Mealhada & & & Torre \\
\hline Murtosa & & & \\
\hline Oliveira de Azeméis & Castela & & \\
\hline Oliveira do Bairro & & & Torre \\
\hline Ovar & & & \\
\hline S. João da Madeira & & & \\
\hline Sever do Vouga & Castelões & & \\
\hline Vagos & & & \\
\hline Vale de Cambra & Castelões & & \\
\hline
\end{tabular}

Tabl. 1. - Corpus de topónimos constituído para o distrito d'Aveiro.

Constituído o corpus para cada um dos distritos, procedeu-se à observação cartográfica dos dados, consultando os mapas interativos disponibilizados pela Direção Geral do Território (DGT), acessíveis online (<http:// mapas.dgterritorio.pt/viewer/index.html>). Esta observação permitiu confirmar a existência do local identificado na base de dados antes consultada e ficar com uma melhor perceção acerca da sua localização geográfica. Os mapas interativos disponibilizados permitem uma observação mais pormenorizada da paisagem toponímica de cada região portuguesa. Apresenta-se, de seguida, o mapa consultado para a localização do concelho de Castro Verde (fig. 3): 


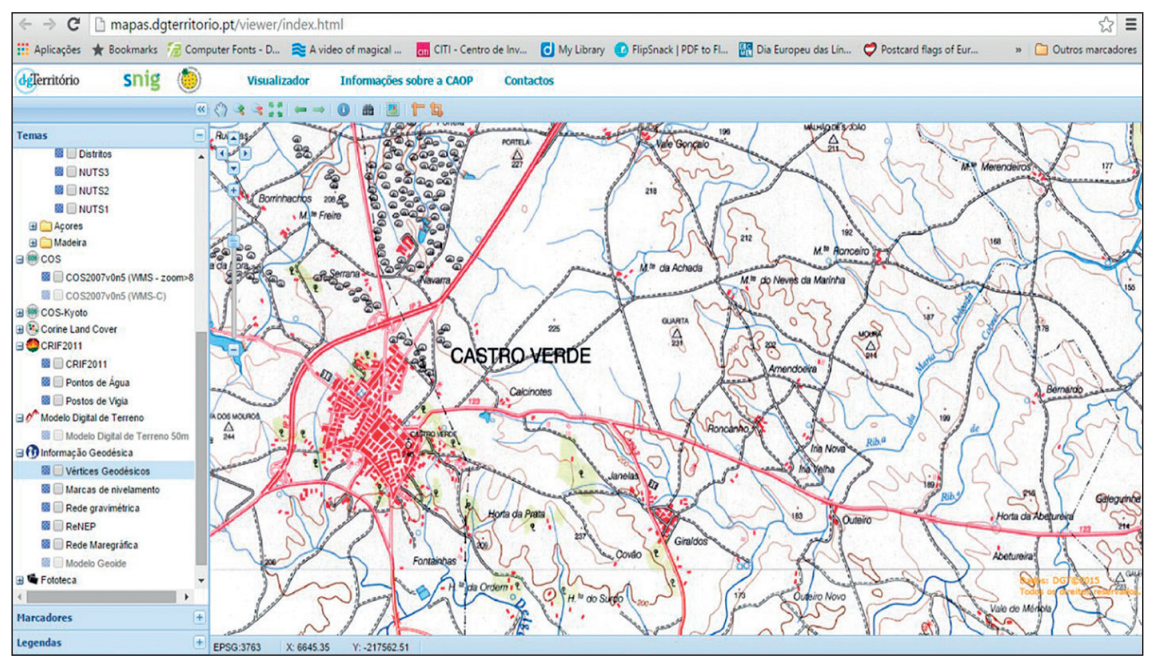

Figura 3. - Pormenor do mapa da DGT para o concelho de Castro Verde. Mapa interativo para o concelho de Castro Verde.

Procedeu-se, de seguida, a uma análise global dos dados, procurando identificar o número de ocorrências para cada um dos termos selecionados. Após esta análise global, os diferentes termos foram estudados, de acordo com a sua estrutura morfológica e sintática.

\section{Resultados}

A análise pormenorizada das tabelas constituídas para cada distrito permitiu verificar a ocorrência de 258 topónimos com a palavra «Castelo», incluindo-se também nesse número produtos derivacionais e composicionais assentes nessa forma de base. $\mathrm{O}$ mesmo procedimento foi observado para a forma «Castro», tendo-se registado 34 ocorrências. Em relação à palavra «Torre», apuraram-se 354 ocorrências, considerando a palavra simples, as formas derivadas e as compostas. Entre os três itens selecionados, «Torre» foi, assim, o termo mais produtivo para a construção de topónimos. O corpus constituído contou com um total de 646 formas toponímicas.

Em termos de distribuição geográfica, o termo «Castelo» e outros que decorrem dessa base são mais frequentes a norte do rio Tejo, com aproximadamente 170 topónimos elencados, embora seja o distrito de Beja aquele que regista maior número de ocorrências (25) e o de Bragança o que regista o número menor (apenas 7). O termo «Torre» regista aproximadamente 230 ocorrências a norte do rio Tejo. Contudo, o distrito de Portalegre, com 41 topónimos registados, é aquele em que a palavra «Torre», os 
derivados desse item e as unidades toponímicas poliléxicas que o incluem aparecem com maior frequência. Bragança é o distrito em que estas palavras menos surgem na construção toponímica. $\mathrm{O}$ termo «Castro» e as suas variações revelaram-se menos produtivos na linguagem toponímica e surgem com maior frequência no Norte do país, com o distrito de Braga a registar 5 locais com designações que apresentam a palavra em apreço, na sua forma simples, derivada ou integrada em sintagmas toponímicos. Relativamente a esta palavra, há quatro distritos onde não se regista qualquer ocorrência de signos toponímicos construídos com recurso a essa forma léxica (Castelo Branco, Évora, Santarém e Setúbal).

Os mapas que a seguir se apresentam (fig. 4) ilustram a distribuição geográfica aproximada dos topónimos, tendo em conta os três nomes em que assentou a pesquisa, nas suas múltiplas ocorrências: simples, resultantes da variação em grau e número, de derivações sufixais, e de expansões, concretizadas em compostos sintagmáticos, mediante a aposição de outros elementos linguísticos.

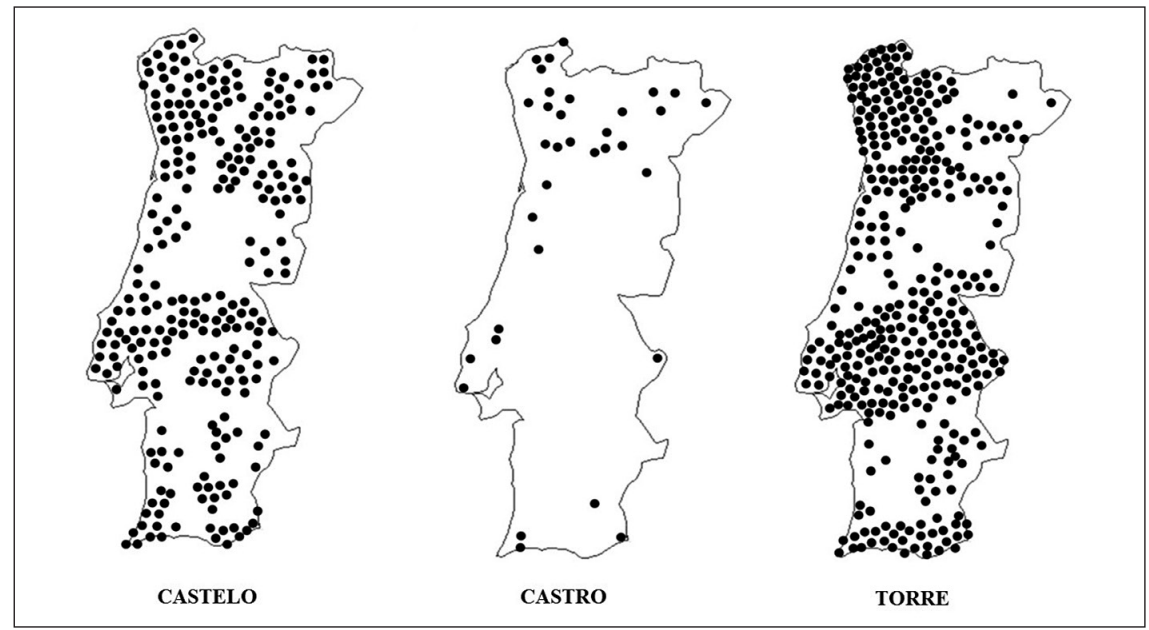

Figura 4. - Cartografia dos topónimos recolhidos.

Os resultados obtidos permitem realizar um estudo assente no processo de formação lexical e da estrutura morfológica do topónimo. Assim, e tendo em conta a heterogeneidade das configurações dos produtos toponímicos coligidos, consideraram-se três grupos: 1) topónimos com a ocorrência do elemento específico simples, ou seja, «Castelo», «Castro» ou «Torre»; 2) topónimos com as variações em grau, número ou com derivações sufixais, como «Torrinha», «Torres» ou «Castelejo»; 3) produtos compositivos que assumem a forma de compostos sintagmáticos, resultantes da expansão 
em torno dos vocábulos simples, mediante a aposição de nomes e adjetivos, com ou sem elementos conetivos, recursos linguísticos importantes para o acréscimo semântico da significação básica do elemento definido como primário, aquando do início da pesquisa (e.g. Quinta do Castelo, Torre de Moncorvo ou Castro Verde). Este último processo revela-se mais complexo, dada a multiplicidade de expansões, quer à esquerda, quer à direita dessas formas «primárias», permitindo problematizar qual o elemento que constitui o núcleo da unidade toponímica poliléxica resultante desse processo de concatenação.

No corpus analisado, das 646 formas recolhidas, 140 são formas simples, 162 são topónimos formados por derivação e 344 por composição (fig. 5):

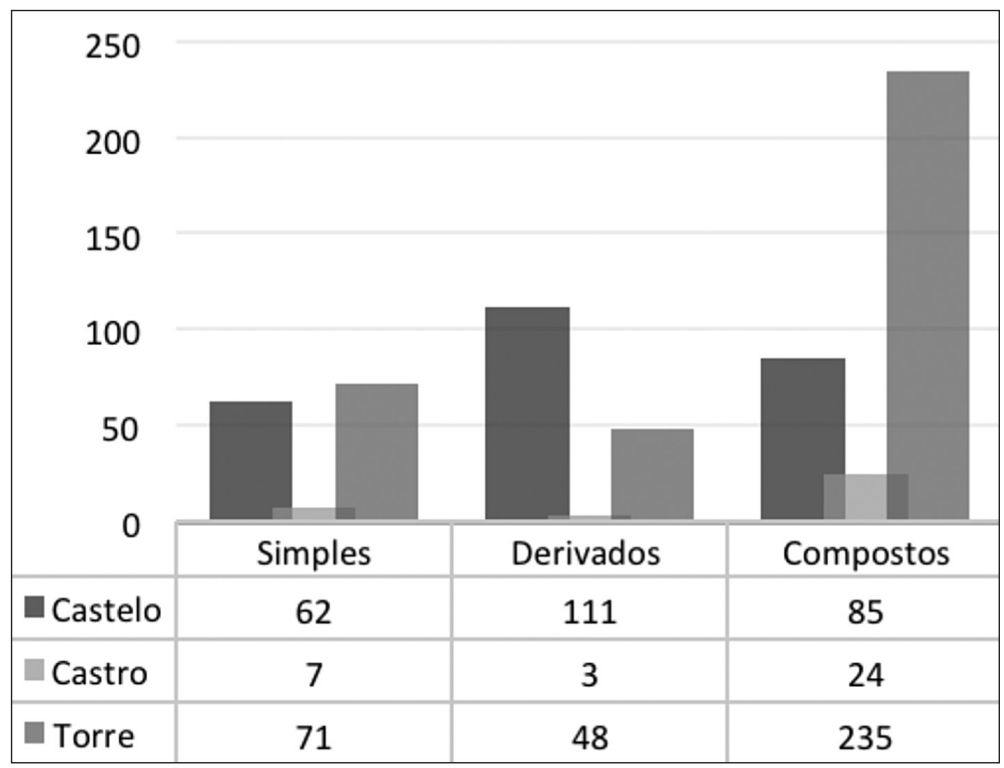

Figura 5. - Distribuição quantitativa dos topónimos, de acordo com a estrutura.

Tendo em conta esta diversidade, o corpus recolhido permitiu a constituição de subcorpora, assentes em critérios de natureza morfológica e sintática. Os topónimos recolhidos podem ser agregados nos conjuntos de estruturas que a seguir se exemplificam (tabl. 2), que constituíram os padrões de análise utilizados neste estudo: 


\begin{tabular}{|c|c|}
\hline TIPOLOGIA DAS FORMAS & EXEMPLOS \\
\hline Formas simples & $\begin{array}{l}\text { Castelo (Albergaria-a-Velha, Aveiro); } \\
\text { Castro (Barcelos, Braga); Torre (Santa } \\
\text { Maria da Feira, Aveiro). }\end{array}$ \\
\hline $\begin{array}{l}\text { Formas com sufixo flexional de } \\
\text { número }\end{array}$ & $\begin{array}{l}\text { Castelos (Barcelos, Braga); Torres (Anadia, } \\
\text { Aveiro). }\end{array}$ \\
\hline Formas com sufixação avaliativa & $\begin{array}{l}\text { Castelinhos (Estremoz, Évora); Torrinha } \\
\text { (Almodôvar, Beja). }\end{array}$ \\
\hline Formas com sufixos derivacionais & $\begin{array}{l}\text { Castelhana (Vila Nova de Famalicão, } \\
\text { Braga). }\end{array}$ \\
\hline $\begin{array}{l}\text { Compostos sintagmáticos com } \\
\text { elementos conetivos }\end{array}$ & $\begin{array}{l}\text { Póvoa do Castelo (Anadia, Aveiro); Castelo } \\
\text { de Paiva (Castelo de Paiva, Aveiro); Monte } \\
\text { Novo da Quinta do Castelo (Beja); Santa } \\
\text { Maria do Castelo (Idanha-a-Nova, Castelo } \\
\text { Branco); Quinta do Castelo do Ferronho } \\
\text { (Freixo de Espada à Cinta, Guarda); Trás } \\
\text { do Castelo (Vieira do Minho, Braga); } \\
\text { Castro de S. Jorge (Águeda, Aveiro); Chão } \\
\text { dos Castros (Terras de Bouro, Braga); } \\
\text { Fragas da Torre (Arouca, Aveiro); Monte da } \\
\text { Torre Velha (Serpa, Beja); Torre de Dona } \\
\text { Chama (Mirandela, Bragança). }\end{array}$ \\
\hline $\begin{array}{l}\text { Compostos sintagmáticos sem } \\
\text { elementos conetivos }\end{array}$ & $\begin{array}{l}\text { Castelo Ventoso (Ourique, Beja); Castro } \\
\text { Vicente (Mogadouro, Bragança); Castro } \\
\text { Mau (Braga); Torre Vã (Ourique, Beja). }\end{array}$ \\
\hline Outras formações & $\begin{array}{l}\text { Castilho (Marco de Canaveses, Porto); } \\
\text { Castilhas (Redondo, Évora); Castromil } \\
\text { (Paredes, Porto); Torralta (Lagos, Faro); } \\
\text { Torraltinha (Lagos, Faro); Torredeita } \\
\text { (Viseu). }\end{array}$ \\
\hline
\end{tabular}

Tabl. 2. - Tipologia das formas toponímicas e exemplos.

\section{Discussão dos resultados}

A toponímia, entendida como um recorte do léxico de uma língua, é um ramo da onomástica e possui como eixo central do seu estudo o topónimo, ou seja, o signo linguístico que identifica um determinado espaço geográfico. Para Rostaing (1961), a finalidade da toponímia é investigar a significação e a origem dos nomes de lugares e as suas transformações. Embora se possa descortinar, através desta definição, a importância do saber linguístico nesse processo, sabemos que a investigação em toponímia se situa numa área de interseção entre a linguística e as questões extralinguísticas, 
de natureza social, histórica e cultural, necessariamente subjacentes à motivação toponímica. De facto, os topónimos espelham, na maior parte dos casos, a realidade do ambiente físico e cultural de uma localidade, revelando características da vegetação, da hidrografia, da fauna, das condições de solo e de relevo ou da localização geográfica. Ilustram, também, crenças, ideologias, factos políticos e históricos. Esse repositório patrimonial permanece no topónimo, mesmo quando a motivação toponímica, ocorrida no ato denominativo, já se extinguiu.

No caso específico deste trabalho, os resultados obtidos permitem-nos verificar a existência de um léxico caracterizado pela variedade das estruturas morfológicas dos signos toponímicos, resultantes das derivações e, sobretudo, das expansões que incluem os termos primários selecionados para a realização deste estudo. Assim, depois de identificadas as sete tipologias toponímicas que vão nortear a presente discussão, pretende-se verificar quais são os processos de formação mais produtivos e as estruturas mórficas e sintáticas recorrentes na toponímia portuguesa, realizando uma descrição morfológica do topónimo, partindo dos subcorpora constituídos.

\subsection{Formas simples}

Com 62 ocorrências, o termo «Castelo», do ponto de vista toponímico, apresenta uma cobertura nacional, surgindo em todos os distritos, na sua forma simples. Para além delas, importa destacar a presença da forma elíptica «Castel» (Condeixa-a-Nova, Coimbra), cuja realização completa terá sido «Castel de Vias», composto que o uso viria a abandonar, em favor do termo simples (Machado, 1993a: 370-371).

Relativamente ao topónimo «Castro», mais raro no corpus constituído, surge em Amarante (Porto), Barcelos (Braga), Braga, Cascais (Lisboa), Paredes de Coura (Viana do Castelo), Póvoa de Lanhoso (Braga) e Vinhais (Bragança), registando-se, assim, sete ocorrências do topónimo, na sua forma simples. A distribuição geográfica dos topónimos com este item lexical, que podemos observar na figura 1, mostra a prevalência de locais com essa designação na região Norte do país. Esta prevalência do termo, nessa região, pode ser justificada por questões históricas: como observa Machado (1993a: 372), o termo «castro» designa, toponimicamente, quase sempre, ruinas de fortificações construídas em montes, provenientes de construções pré-romanas, datadas da Idade do Ferro, que, historicamente, eram características das regiões que hoje integram o Norte do país.

As residências senhoriais com forma de torres surgiram em Portugal nos fins do terceiro quartel do século XII ou no início do quartel seguinte. Multiplicaram-se nos séculos XIII e XIV e ainda se construíram no século XVII 
(Vasconcelos, 1995: 596). Para além das construções senhoriais, do ponto de vista militar, uma torre era, muitas vezes, suficiente para a vigilância e defesa contra o inimigo. Segundo Azevedo (2005: 68), a forma latina «turre» terá originado cerca de 990 topónimos na Península Ibérica. As províncias espanholas onde abundam são La Coruña, Lugo, Pontevedra e Lérida. Em Portugal, os distritos onde o número de ocorrências é maior são os de Viana do Castelo, Braga, Portalegre, Lisboa, Évora e Faro. Aliás, é o próprio Leite de Vasconcelos que faz referência à recorrência do termo «Torre» na toponímia da região de Portalegre:

Na mesma região [Portalegre], como me informa o Sr. Mario Saa, não faltam sítios com o nome de Torre, correspondentes a outras tantas torres, que parece foram antigos magnates: Torre das Areias (Ervedal), Torre do Bispo ou de Lupe (Fronteira) [...] Torre das Galveias. Algumas d'elas igualmente residência de comendadores (de Avis)? (Vasconcelos, 1995: 600-601)

A generalização da construção pode justificar o facto de ser este o termo simples com maior número de ocorrências na toponímia de Portugal Continental, quando comparado com os itens «Castelo»e «Castro». Registaramse 71 ocorrências deste topónimo, na sua forma simples, mas, conforme já se referiu na secção «Resultados», trata-se de um termo bastante frequente na construção de topónimos compostos ou com formas dele derivadas, como, de resto, tão bem observa Leite de Vasconcelos (1995: 590-610).

Uma primeira abordagem ao corpus constituído permite concluir, também, que são mais frequentes as formas compostas, resultantes de processos de concatenação, que integram os vocábulos que se selecionaram e outros itens lexicais.

\subsection{Formas com sufixo flexional de número}

Menos frequentes do que as formas do singular, há que referir a presença da flexão em número das formas de base convocadas para a realização deste estudo. Em todas elas, a flexão em número resulta da adição do morfema de plural característico do português, um $-s$ que se realiza [S], em português europeu. Registam-se cinco ocorrências para o topónimo «Castelos», em Barcelos (Braga), Estremoz (Évora), Portimão (Faro), Santiago do Cacém (Setúbal) e Tavira (Faro). Em relação ao termo «Castro», não se registaram formas de plural, em ocorrências toponímicas constituídas, apenas, por um item lexical. No entanto, importa salientar a ocorrência da forma «Crastos» (Lagoa, Faro), onde se regista a metátese da consoante vibrante líquida - $r$ Já a forma «Torres» surge em Anadia (Aveiro), Arcos de Valdevez (Viana do Castelo), Palmela (Setúbal), Setúbal, Trancoso (Guarda), Vila Nova de Famalicão (Braga) e Vila Verde (Braga), num total de sete ocorrências. 
Para além das formas de plural comuns, importa destacar a presença do termo «Castela», que, do ponto de vista etimológico, significa «os castelos» (Machado, 1993a: 370). O termo provém do latim castellum, que, como é próprio dos nomes neutros latinos, apresenta a desinência - $a$, no plural. Contudo, o termo, hoje, não encerra essa noção de plural. Na sua forma simples, o topónimo «Castela» surge, nas bases de dados consultadas, em Figueira da Foz (Coimbra), Guarda, Penacova (Coimbra) e Oliveira de Azeméis (Aveiro).

\subsection{Formas com sufixos avaliativos}

Um procedimento que se revela bastante produtivo na construção de topónimos é a sufixação avaliativa, que não altera a categoria sintática da forma derivante. No corpus toponímico em análise, encontram-se várias formas que resultam desse processo, recorrendo a múltiplos sufixos. Os exemplos apresentados em (1) ilustram os diferentes sufixos avaliativos utilizados na construção dos topónimos:

(1)

a. Castelinho/Castelinhos

b. Castelejo/Casteleja

c. Castelonito

d. Castrelos

e. Torrinha/Torrinhas

f. Herdade do Casteleto

Os exemplos semelhantes aos apresentados em (1a) e (1e) assumem-se como os mais produtivos, registando-se um total de 45 ocorrências com o sufixo -inh-. O topónimo «Castelinho» surge em Marco de Canaveses (Porto), Ourique (Beja) e Santo Tirso (Porto) e, no plural, em Estremoz (Évora), registando-se, ainda, compostos sintagmáticos com o termo, quer no singular, quer no plural (Monte dos Castelinhos, Elvas, Portalegre; Quinta dos Castelinhos, Ourém, Leiria; Quinta do Castelinho, São João da Pesqueira, Viseu; e Castelinhos de S. Jorge, Santa Marta de Penaguião, Vila Real).

«Torrinha», enquanto diminutivo de «torre», é uma das formas mais frequentes na construção toponímica com recurso a sufixação avaliativa, com 16 ocorrências, na sua forma do singular, e 3 com a flexão no plural. A forma «Torrinha» surge em vários compostos sintagmáticos: Torrinha Nova (Beja); Quinta da Torrinha (Fundão, Castelo Branco; Albufeira, Faro; Portimão, Faro; Vila Nova de Foz Côa, Guarda e Odivelas, Lisboa); Monte da Torrinha (Évora; Montemor-o-Novo, Évora; Arronches, Portalegre; e Avis, Portalegre) e Casal Torrinha (Santarém). Esta forma com sufixo 
avaliativo surge, ainda, no plural (Torrinhas) em Odemira (Beja), Castelo Branco e Batalha (Leiria).

A utilização dos sufixos avaliativos relaciona-se com a cronologia da Reconquista e do repovoamento (Azevedo, 2005: 71; Rio-Torto, 2016: 372). Um estudo da distribuição do sufixo -inh- na toponímia, estudada e cartografada por Diego Catalán, permite verificar que «em Portugal, à medida que avançamos em direção ao Sul, a ocorrência de -inh- vai aumentando, comparativamente com a do sufixo -el-» (Azevedo, 2005: 71) que, a norte do Douro, se assume como mais produtivo. No corpus coligido, e tendo em conta os três termos que orientaram a pesquisa realizada, verifica-se que das 45 formas com o sufixo avaliativo -inh- (e.g. Castelinho, Torrinha), somente 5 ocorrem nos distritos situados a norte do rio Douro (Porto, Viana do Castelo e Vila Real). Na verdade, como observa Rio-Torto (2016: 372), assistiu-se a uma inflação de produtos toponímicos com a presença deste sufixo, sobretudo nas regiões do Sul. Relativamente ao sufixo -el-, refira-se a presença do topónimo «Castrelos», no concelho de Bragança, não se registando qualquer ocorrência deste sufixo noutras regiões.

O exemplo (1b) resulta da aposição do sufixo - ej-, também utilizado como sufixo avaliativo, transmitindo a ideia de um «pequeno castelo». A forma «Castelejo» regista seis ocorrências, como elemento único, e surge combinada em sintagmas como Monte de Castelejo (Mértola, Beja), Monte do Castelejo (Ourique, Beja), Quinta do Castelejo (Gouveia, Guarda), Presa de Castelejo (Ansião, Leiria) e Porto Castelejo (Santa Comba Dão, Viseu). Saliente-se, ainda, o registo da forma «Os Castelejos», iniciada com o determinante artigo definido, em Pampilhosa da Serra (Coimbra).

O termo apresentado em (1c) é uma forma que apresenta o sufixo -it-, que, não sendo dos mais produtivos, em português europeu, surge em várias formas que não integram o universo toponímico (e.g. carrito, pãozito), sobretudo na região Sul do país (Rio-Torto, 2016: 372). Aliás, a ocorrência do termo regista-se em Ourique, no distrito de Beja. A presença deste sufixo, nesta região, pode dever-se a uma influência do leonês:

Quizá -ito - concluye Catalán-, siglos antes de imponerse en castellano, gozó de especial prestigio en el bajo leonés de Salamanca y desde allí, durante el siglo xIII, se expandió por Extremadura y Huelva, siendo exportado simultáneamente al Alentejo y el Algarve. (Trapero, 2000: 222)

A forma presente em (1d) pode ser entendida como diminutivo de «castro», à qual se acrescentou o sufixo latino -llus-, um sufixo de diminutivo. A forma «Castrelos» será, assim, uma possível forma antiga, que dará origem ao nome «castelo». 
Por último, a forma «Casteleto» (1f), presente no sintagma «Herdade do Casteleto» (Estremoz, Évora), evidencia outra possibilidade de formação de diminutivos, mas pouco produtiva na construção toponímica, tendo em conta o corpus constituído no âmbito deste estudo.

De acordo com os exemplos apresentados em (1), parece lícito considerar que a utilização dos sufixos de diminutivo se rege por uma regra de menorização objetiva da realidade (uma construção ou um espaço de menores dimensões), atinente ao seu valor etimológico.

\subsection{Formas com sufixos derivacionais}

Os exemplos apresentados em (2) referem-se a uma mesma forma, resultante da aposição de um sufixo derivacional à forma de base que, neste caso, é «Castelo»:

(2)

a. Castelã/Castelãs

b. Castelães

c. Castilhão

d. Castelhão/Castelhãos

e. Castelão/Castelãos

f. Castelhana/Castelhanas

g. Castelhano/Castelhanos

h. Castelões

A aposição do sufixo origina um topónimo que regista várias formas gráficas. Assim, «Castelões» (2h), como observa Machado (1993: 370) apresenta o mesmo significado que «Castelhanos» (cf. $2 \mathrm{f} \mathrm{e} 2 \mathrm{~g}$ ). Esta forma, segundo o autor, poderá ser uma grafia antiga de «Castelão» (2e), anterior ao processo de síncope do - $n$ - intervocálico. São, pois, sufixos que podem transmitir a ideia de proveniência e de origem.

Para além dos exemplos antes apresentados, os elencados em (3) ilustram a produtividade do sufixo -eir-, em topónimos simples e compostos. Tal morfema, como observam Cunha e Cintra (1994: 96), pode apresentar seis sentidos, entre os quais se acham «a) ocupação, ofício, profissão». O «casteleiro» remete, assim, para um funcionário real, tenente ou governador de um castelo (ou fortaleza) de uma importância menor (Vasconcelos, 1995: 463), tendo permanecido a memória da função na motivação toponímica:

(3)

a. Casteleiro

b. Monte dos Casteleiros 
As formas apresentadas em (4) remetem para vocábulos espanhóis (Machado, 1990a: 370). Se, relativamente ao termo apresentado em (4a) é possível encontrar um significado, pois remete para o ato de supervisionar obras numa fortaleza ou num castelo, já o termo apresentado em (4b) apresenta um significado ainda obscuro, na língua portuguesa. De facto, uma análise do sentido do sufixo - ad- permite-nos considerar que transmite a ideia de multidão (Cunha \& Cintra, 1994: 96), admitindo-se, por isso, que o local em apreço teria, entre os seus residentes, um grande número de castelhanos, aquando do ato de denominação.

(4)

a. Castelaria

b. Castelhada

Tendo como forma de base a palavra «torre», no corpus constituído registam-se as formas apresentadas em (5), com a presença de sufixos derivacionais:

a. Horta de Torrejais

b. Torrejão/Torrejões

c. Torrejana

d. Torrelha

e. Torrinheiras

Relativamente à palavra apresentada em (5a), «Torrejais» é um derivado da forma «torrejo», que, por sua vez, deriva de «torre» (Machado, 1990c: 1421). As formas (5b) e (5c) provêm do adjetivo «torrejano», que é sinónimo de «torrejão». Relativamente ao exemplo apresentado em (5d), poderá ser entendido como um derivado de «torre» (Machado, 1990c: 1421) e o topónimo referido em (5e) surge a partir do nome feminino «torrinheira».

\subsection{Definição do núcleo dos compostos sintagmáticos}

Como já se referiu, os produtos toponímicos fruto de processos composicionais são os mais recorrentes no corpus constituído e são, também, os que mostram configurações formais mais heterogéneas. Os compostos são palavras com uma estrutura interna complexa, resultantes de um processo de formação, designado por composição, que consiste na concatenação de duas ou mais palavras e/ou radicais (Mateus et al., 1990: 479; Rio-Torto, 2016: 461), com ou sem elementos conetivos de permeio.

A adjunção dessas palavras na construção dos topónimos coloca algumas questões que se prendem com a determinação do núcleo do sintagma toponímico. Essa definição pode acarretar algumas dificuldades tendo em 
conta que os compostos toponímicos, à semelhança dos demais nomes compostos, são formados por reanálise, uma regra não-morfológica de formação de palavras, que atribui uma categoria sintática (no caso dos topónimos, um nome) a uma categoria sintagmática (Mateus et al., 1990: 481). É esse processo que vai permitir que qualquer unidade sintagmática possa ser reanalisada como uma palavra e, assim, garantir uma unicidade semântica, propriedade característica dos produtos toponímicos. De facto, e à semelhança do que acontece com muitos nomes compostos, estas unidades poliléxicas apresentam um sentido unitário/holístico (Rio-Torto, 2016: 462), embora registem variações ao nível da sua constituição morfológica e no seu grau de lexicalidade.

Como se pode, então, determinar o núcleo de um sintagma toponímico? Para Rio-Torto (2016: 500), a identificação do núcleo de um composto faz-se tendo em conta três dimensões:a categorial, a morfológica e a semântica. No caso dos topónimos, a dimensão categorial é pouco relevante, pois, independentemente dos elementos compositivos que o constituam, estamos sempre perante nomes próprios. No que se refere à dimensão morfológica, esta parece-nos ter uma importância reduzida, pois os traços de género e de número dados pelos elementos compositivos nem sempre se revelam pertinentes para a definição do elemento nuclear, atendendo a que, por se tratarem de nomes próprios, os topónimos não admitem formas de plural. Há, contudo, situações em que a forma de plural de um dos elementos da concatenação pode contribuir para a definição do núcleo, como acontece em «Torres de Apra» (Loulé, Faro).

Assim, perante um produto toponímico de estrutura composicional, parece-nos que a dimensão mais importante para a determinação do seu núcleo é a interpretação semântica da palavra composta (Mateus et al., 1990: 482). Observem-se os seguintes exemplos:

(6)
a. Póvoa do Castelo
b. Viana do Castelo
c. Outeiro do Castro
d. Casal de Castro
e. Fragas da Torre
f. Coutada da Torre

Os exemplos apresentados em (6) atestam a ocorrência de sintagmas toponímicos em que se verifica que os termos «Castelo», «Castro» ou «Torre» se assumem como especificadores de um núcleo e não como núcleo do sintagma, i.e., o elemento que se encontra mais à esquerda. Como há pouco se referiu, a interpretação semântica contribui para a definição do núcleo, 
estando esta generalizada através do uso que se faz dessas formas toponímicas em que, muitas vezes, a supressão dos sintagmas preposicionais presentes na concatenação não constitui um obstáculo para o reconhecimento do topónimo, como acontece em (6a) e (6b), admitindo-se a possibilidade de tal supressão também se registar nos exemplos (6c) a (6f), ainda que esse uso se circunscreva a um limite geográfico mais restrito. Verifica-se, assim, que ao lado da interpretação semântica, os fatores de ordem pragmática desempenham, igualmente, um papel importante na construção de significação de um topónimo e, indo mais longe, de qualquer nome próprio.

Em sintagmas toponímicos como os que se apresentam em (7), onde os termos selecionados para a presente reflexão surgem em posição medial, no contexto do sintagma criado, nem sempre é fácil a determinação do núcleo:

(7)
a. Figueira de Castelo Rodrigo
b. Quinta do Castelo do Ferronho
c. Monte do Castelo Velho
d. Quinta da Torre Alva
e. Vale da Torre de Baixo

Nestes casos, os termos que constituíram o ponto de partida para esta reflexão não ocupam a posição do núcleo, não ficando claro se esta função é desempenhada pelo elemento que se encontra mais à esquerda ou pelos restantes. De facto, quando se analisa a estrutura do sintagma toponímico apresentado em (7a), pode-se considerar que o núcleo é constituído pelo primeiro elemento (Figueira), construindo-se o restante sintagma com uma sucessão de especificadores. Nestes casos, os elementos especificadores contribuem para a interpretação semântica do nome situado à sua esquerda, ajudando a construir uma referência.

Contudo, nesse mesmo exemplo, a sequência «Castelo Rodrigo» parece assumir a função de um átomo sintático (Di Sciulo \& Williams, 1987), constituindo uma unidade de sentido que, do ponto de vista semântico, parece autorizar a possibilidade de os elementos mais à direita assumirem a função de núcleo, o mesmo acontecendo nos exemplos (7b) a (7e). No entanto, nos compostos (7b) a (7e) não é de excluir a possibilidade de agrupar os elementos Quinta do Castelo [do Ferronho], Monte do Castelo [Velho], Quinta da Torre [Alva] e Vale da Torre [de Baixo], porque, do ponto de vista semântico, tais unidades poliléxicas são aceitáveis, em português.

No caso dos compostos toponímicos apresentados em (7) verifica-se que, enquanto compostos sintagmáticos, o seu núcleo pode ser atribuído ao constituinte da esquerda ou aos constituintes da direita. No entanto, o 
estatuto de núcleo do composto pode mesmo não ser atribuído a qualquer dos seus constituintes, no caso das palavras exocêntricas, i. e., sem núcleo (Mateus et al., 1990: 481; Rio-Torto, 2016: 502), algo que nos parece acontecer com os topónimos apresentados em (8):

(8)
a. Castelo de Vide
b. Castelo Branco
c. Castro do Alferce
d. Castro Verde
e. Torre das Vargens

De facto, nos exemplos apresentados em (8), e ao contrário do que acontece nos exemplos coligidos em (6) e (7), a omissão de parte do sintagma toponímico levanta problemas relativamente ao reconhecimento do referente geográfico, não sendo fácil a determinação de qualquer elemento nuclear, porque neles «nenhuma das bases funciona como núcleo semântico» (Rio-Torto, 2016: 114). Embora possamos sempre considerar que o elemento mais à esquerda constitui o núcleo, que se encontra seguido do seu especificador, o processo de reanálise, subjacente à formação do topónimo composto, e a interpretação semântica conduzem à construção de uma forma lexicalizada, que não pode existir sem a adjunção dos elementos basilares, com o auxílio da preposição, como em (8a), (8c) e (8e) ou sem o elemento conetivo, como acontece em (8b) e (8d).

Em topónimos como os apresentados em (8), a construção assenta na adjunção de um termo genérico a um termo específico, originando um novo termo, aparentemente indissolúvel. Nessa concatenação, o termo genérico tende a perder o seu sentido próprio e passa a ser apenas um complemento do termo específico e a junção dos dois termos origina um topónimo que ilustra uma característica habitual dos nomes compostos: «o resultado semântico não se subsume na simples adição dos semantismos das bases» (Rio-Torto, 2016: 110). Numa palavra, o comportamento desses produtos toponímicos assemelha-se ao dos demais nomes compostos, registandose um comportamento unitário ou tendencialmente unitário, como se de uma palavra única se tratasse. Aliás, os compostos toponímicos parecem constituir um repositório das características próprias da composição sintagmática lexicalizada.

Por um lado, apresentam um alto grau de fixidez dos seus elementos, inviabilizando qualquer processo de substituição; por outro, não admitem a inclusão de outras unidades lexicais, sob pena de o referente geográfico ficar irreconhecível; para além disso, e porque são constituídos, sobretudo, por unidades léxicas nominais, apresentam uma ordem fixa dos seus 
constituintes: um determinado seguido de um determinante (Rio-Torto, 2016: 462). Tais relações resultam, como salienta Nascimento (2013: 215), de relações formais e semânticas que o uso acabou por consagrar. De resto, no caso dos topónimos, a questão da consagração pelo uso parece ser axial na definição das preferências e na generalização de determinadas formas, entre as populações.

Assim, e embora possamos dizer que o núcleo de uma concatenação toponímica é, geralmente, o elemento que se encontra mais à esquerda, a generalização absoluta não poderá ser considerada. De facto, o uso convencionou que, em muitos topónimos, a omissão dos elementos à direita do núcleo não é impeditiva do reconhecimento do referente, como mostram os exemplos apresentados em (6), ou outros que, não incluindo as palavras que se selecionaram para a realização desta pesquisa, confirmam essa possibilidade, como os que surgem em (9):

(9)
a. Viana do Alentejo
b. Vila Franca do Campo
c. Vila Franca de Xira
d. Montemor-o-Novo
e. Montemor-o-Velho
f. Celorico da Beira
g. Celorico de Basto

Como já foi referido, em casos como estes, a omissão dos constituintes mais à direita não obstaculiza o reconhecimento da unidade geográfica designada, contribuindo para isso o conhecimento que os falantes detêm do seu mundo circundante. De facto, como acontece na generalidade das palavras de uma língua, o que rege a utilização dos topónimos é a capacidade de o referente ser identificado, com base nas propriedades locativas que o termo toponímico contém. No entanto, essas propriedades não se cingem às características objetivas da realidade denominada ou ao material linguístico presente no produto toponímico, pois, uma análise transversal do corpus constituído permite verificar que o mesmo nome possibilita a identificação de diferentes lugares, que, por sua vez, correspondem a diferentes realidades. Assim, e atentando nos exemplos apresentados em (9), a identificação dos locais é possibilitada pelo conhecimento que os falantes têm do mundo e pelas experiências e vivências regionais, o que nos permite considerar que, para um habitante de Évora, ir a Viana é deslocar-se a Viana do Alentejo e, para um habitante de Melgaço, é ir a Viana do Castelo.

Contudo, e embora seja um processo menos frequente, em alguns topónimos, é o termo especificador que parece assumir o comando do sin- 
tagma toponímico, dando-se a elipse do elemento nuclear. Tal acontece, por exemplo, com o topónimo apresentado em (10):

a. Torre de Moncorvo

b. [Torre de] Moncorvo

O exemplo apresentado em (10) parece constituir um caso de um núcleo relativizado, onde o núcleo do sintagma toponímico é elidido e, assim, tal função é transferida para o elemento sobrante, o constituinte mais à direita, que comporta a informação relevante para o reconhecimento da unidade toponímica que se pretende nomear. De facto, em casos como o apresentado em (10), a generalização da forma mais à direita assenta em critérios de análise semântica e pragmática, pois, como comprovam outros exemplos da toponímia portuguesa, é possível elidir os constituintes colocados mais à esquerda do sintagma, sem pôr em causa o reconhecimento do referente toponímico. Veja-se o que acontece com os exemplos apresentados em (11):
a. Vila Nova de Gaia
b. [Vila Nova de] Gaia
c. Vila Nova de Ourém
d. [Vila Nova de] Ourém
e. Vila Nova de Famalicão
f. [Vila Nova de] Famalicão
g. Vila Nova de Milfontes
h. [Vila Nova de] Milfontes

No entanto, é curioso verificar que, com outros topónimos, apesar de apresentarem uma estrutura composicional idêntica, não se registou a generalização do elemento mais à direita como termo privilegiado para nomear o referente toponímico, como se pode verificar em (12):
a. Vila Franca de Xira
b. *[Vila Franca de] Xira

\subsection{Compostos sintagmáticos com elementos conetivos}

Entre os topónimos compostos com elementos conetivos, a estrutura que se revelou mais produtiva é a que apresenta dois nomes ligados por uma preposição, como os apresentados em (13): 
(13)
a. [[Póvoa $\left.]_{N}[\text { do }]_{\text {PREP }}[\text { Castelo }]_{N}\right]$
b. $\left[[\text { Castelo }]_{\mathrm{N}}[\text { de }]_{\text {PREP }}[\text { Paiva }]_{\mathrm{N}}\right]$
c. $\left[[\text { Castro }]_{\mathrm{N}}[\text { de }]_{\text {PREP }}[\text { Avelãs }]_{\mathrm{N}}\right]$
d. $\left[[\text { Quinta }]_{\mathrm{N}}[\mathrm{do}]_{\text {PREP }}[\text { Castro }]_{\mathrm{N}}\right]$
e. $\left[[\text { Torre }]_{N}[\mathrm{da}]_{\text {PREP }}[\text { Marinha }]_{N}\right]$
f. $\left[[\text { Vale }]_{N}[d a]_{\text {PREP }}[\text { Torre }]_{N}\right]$

Em topónimos compostos como os apresentados em (13), o elemento à direita especifica o nome anteposto à preposição, registando-se 72 ocorrências com a presença da preposição «de», 94 com a forma preposicional contraída com o masculino do determinante artigo definido, no singular ou no plural («do»/《dos») e 156 com a forma «da» ou «das», perfazendo um total de 322 sintagmas toponímicos concatenados com o auxílio de uma preposição simples ou contraída.

Os exemplos apresentados em (14) resultam da aposição de nomes e de adjetivos, que conferem às formas simples um crescente grau de especificação.

a. $\left[[\text { Monte }]_{\mathrm{N}}[\text { Novo }]_{\text {ADJ }}[\mathrm{da}]_{\text {PREP }}[\text { Quinta }]_{\mathrm{N}}[\mathrm{do}]_{\text {PREP }}[\text { Castelo }]_{\mathrm{N}}\right]$

b. $\left[[\text { Monte }]_{\mathrm{N}}[\text { Novo }]_{\mathrm{ADJ}}[\mathrm{do}]_{\mathrm{PREP}}[\text { Castelo }]_{\mathrm{N}}\right]$

c. $\left[[\text { Monte }]_{\mathrm{N}}[\mathrm{do}]_{\text {PREP }}[\text { Castelo }]_{\mathrm{N}}[\text { Velho }]_{\text {ADJ }}\right]$

d. $\left[[\text { Monte }]_{\mathrm{N}}[\mathrm{da}]_{\mathrm{PREP}}[\text { Torre }]_{\mathrm{N}}[\text { Velha }]_{\mathrm{ADJ}}\right]$

e. $\left[[\text { Torre }]_{\mathrm{N}}[\mathrm{de}]_{\mathrm{PREP}}[\text { Dona }]_{\mathrm{N}}[\text { Jerónima }]_{\mathrm{N}}\right]$

As unidades poliléxicas toponímicas apresentadas em (14) podem apresentar sequências diversificadas, como em (14a), constituída por um nome, seguido de um adjetivo, ligados por uma preposição a um nome que se liga a outro nome, também através de um elemento conetivo. Assim, surgem estruturas combinadas em que se distinguem dois grandes segmentos dentro do nome composto, como em (14a) [Monte Novo] e [Quinta do Castelo], podendo estes ser considerados átomos sintáticos. Formas como a que surge em (14b) resultam da aposição de um nome a um adjetivo, sequência que se liga a outro nome, através de uma preposição. Os exemplos (14c) e (14d) ilustram a adjunção de um nome a um sintagma constituído por um nome e um adjetivo, com o recurso a uma preposição. As estruturas apresentadas em (14b), (14c) e (14d) apresentam um processo de formação em que as categorias sintáticas convocadas são as mesmas (nome, preposição e adjetivo), mas assumem diferentes configurações sintagmáticas, ora surgindo a sequência nome+adjetivo à esquerda do sintagma (cf. 14b), ora à direita (cf. 14c e 14d). O sintagma toponímico apresentado em (14e) resulta da adjunção de uma sequência de nomes, em torno do termo gené- 
rico «Torre», assumindo a sequência «Dona Jerónima» a configuração de um átomo sintático, que particulariza a noção espacial, singularizando-a e transformando-a num sintagma toponímico antroponomástico, como, de resto, é bastante frequente com o termo «torre» (e.g. Torre de Dona Chama, Bragança; Torre de Sequeira, Elvas, Portalegre; Torre de Madureira, Paredes, Porto).

As estruturas apresentadas em (15) revelam-se pouco produtivas, resultando da junção de uma locução prepositiva a um nome, como em (15a), ou de um quantificador numeral, anteposto a um nome e colocado após a preposição (15b).

a. $\left[[\text { Trás }]_{\text {PREP }}[\text { do }]_{\text {PREP }}[\text { Castelo }]_{N}\right]$

b. $\left[[\text { Bairro }]_{N}[\text { dos }]_{\text {PREP }}[\text { Sete }]_{\text {QUANT }}[\text { Castelos }]_{N}\right]$

Assim, no que diz respeito aos sintagmas toponímicos com elementos conetivos, parece ser possível afirmar que as duas formações compostas mais produtivas no corpus recolhido foram as que apresentam as estruturas descritas em (13) e (14), e que podem ser assim sintetizadas:

\begin{tabular}{|c|}
\hline 1. $\mathrm{N}+\mathrm{PREP}+\mathrm{N}(+\mathrm{ADJ} /+\mathrm{N}$ \\
\hline $2 . \mathrm{N}+(\mathrm{ADJ})+\mathrm{PREP}+\mathrm{N}+\mathrm{N}$ \\
\hline
\end{tabular}

Entre as formas com elementos conetivos, merecem, ainda, uma breve análise estruturas em que a concatenação não se faz recorrendo a uma preposição mas a uma conjunção (cf. 16a), ou, até, a uma sequência de estrutura tripartida, assindética entre o primeiro e segundo elementos constitutivos do topónimo, e sindética, entre o segundo e o terceiro elementos (cf. 16b). Registe-se, ainda, a existência de compostos em que os elementos são ligados por conjunções e preposições (16c). Os exemplos apontados em (16) ilustram os tipos de estrutura descritos:

a. $\left[[\text { Torres }]_{\mathrm{N}}[\mathrm{e}]_{\mathrm{CoNJ}}[\text { Cercas }]_{\mathrm{N}}\right]$

b. $\left[[\text { Canda }]_{\mathrm{N}},[\varnothing][\text { Esteves }]_{\mathrm{N}}[\mathrm{e}]_{\mathrm{CONJ}}[\text { Torre }]_{\mathrm{N}}\right]$

c. $\left[[\text { Torre }]_{\mathrm{N}}[\mathrm{e}]_{\text {CONJ }}[\text { Seio }]_{\mathrm{N}}[\mathrm{de}]_{\mathrm{PREP}}[\text { Ouro }]_{\mathrm{N}}\right]$

\subsection{Compostos sintagmáticos sem elementos conetivos}

Os compostos sintagmáticos sem elementos conetivos são frequentes, originando estruturas constituídas por N+ADJ, como as apresentadas em (17): 
(17)
a. [[Castelo $\left.]_{\mathrm{N}}[\text { Ventoso }]_{\mathrm{ADJ}}\right]$
b. $\left[[\text { Castelo }]_{\mathrm{N}}[\text { Melhor }]_{\mathrm{ADJ}}\right]$
c. $\left[[\text { Castro }]_{N}[\text { Verde }]_{\mathrm{ADJ}}\right]$
d. [[Torre $\left.]_{\mathrm{N}}[\mathrm{V} \tilde{\mathrm{a}}]_{\mathrm{ADJ}}\right]$
e. [[Torres $\left.]_{\mathrm{N}}[\text { Vedras }]_{\mathrm{ADJ}}\right]$

Os adjetivos concatenados aos nomes implicam uma valoração aspetual do termo genérico, apresentando o mesmo significado que detêm na linguagem comum e fornecendo especificações de índole estética (18a), acerca da dimensão (18b), do posicionamento do local (18c), informações sobre particularidades climáticas (18d), cromáticas (18e) ou cronológicas (18f), entre outras:

(18)

a. $\left.[\text { Quinta }]_{\mathrm{N}}[\mathrm{da}]_{\text {PREP }}[\text { Torre }]_{\mathrm{N}}[\text { Bela }]_{\mathrm{ADJ}}\right]$

b. $\left.[\text { Torre }]_{\mathrm{N}}[\mathrm{Alta}]_{\mathrm{ADJ}}\right]$

c. $\left.[\text { Torre }]_{\mathrm{N}}[\text { Cimeira }]_{\mathrm{ADJ}}\right]$

d. [Castelo $\left.]_{N}[\text { Ventoso }]_{A D J}\right]$

e. $\left.[\text { Castro }]_{\mathrm{N}}[\text { Verde }]_{\mathrm{ADJ}}\right]$

f. $\left.[\text { Castelo }]_{\mathrm{N}}[\mathrm{Novo}]_{\mathrm{ADI}}\right]$

Com menor frequência, surgem sequências em que um dos termos selecionados para a constituição do corpus aparece associado a um antropónimo. Embora o sintagma toponímico não apresente um elemento conetivo, pode-se considerar que esse conetor está subentendido, como mostra o exemplo apresentado em (19a):

(19)

a. $\left[[\text { Castelo }]_{N}[\text { Viegas }]_{N}\right]$

Registam-se, ainda, sintagmas toponímicos com a estrutura N+N+ADJ, que constituem, no fundo, expansões da estrutura já descrita em (17) e que o exemplo apresentado em (20) ilustra:

a. $\left[[\text { Casal }]_{\mathrm{N}}[\text { Castelo }]_{\mathrm{N}}[\text { Branco }]_{\mathrm{ADJ}}\right]$

\subsection{Outras formas}

Alguns topónimos ocorrentes apresentam outras estruturas, com especificidades que não se enquadram nas tipologias anteriormente descritas. Tais exemplos podem ser observados em (21): 
(21)

a. Castilho/Castilhas

b. Castromil

Assim, as formas «Castilho» e «Castilhas» (21a) são de origem espanhola, significando, no primeiro caso, «castelo». O segundo caso parece ser uma forma redundante de plural. De facto, ao ser introduzida na língua portuguesa, a palavra não surge com a noção de plural associada, com origem na desinência - $a$-, própria dos plurais neutros latinos. Assim, a essa forma, acrescentou-se a marca de número própria da língua portuguesa (Machado, 1990a: 370). O topónimo apresentado em (21b) parece ser uma forma aglutinada da expressão «Castro Mil» (Machado, 1990: 373).

Alguns topónimos admitem na sua formação uma idiomatização do aumentativo ou do diminutivo (Sandmann, 1991: 31). Este processo «permite que um sufixo derivacional de grau não seja o último da série de afixos, admitindo inclusive outro sufixo de grau e até de semântica oposta» (Sandmann, 1991: 31). Embora o topónimo apresentado em (22a) não resulte de um processo de dupla sufixação, estamos em crer que aqui também se regista um processo de idiomatização:

a. Torraltinha

b. Torralta

c. Torredeita

De facto, o termo resulta de uma aglutinação do nome «torre» e do adjetivo «altinha». Esta forma, por sua vez, resulta da adjunção de um sufixo que traduz a intensidade de uma qualidade ou de uma propriedade (Mateus et al., 2003: 389). Assim, como nos mostra o exemplo (22a), o processo de composição e o de derivação não se excluem, podendo originar formas que, semanticamente, parecem contraditórias. O exemplo (22b) constitui a forma de base do topónimo apresentado em (22a), não apresentando, por isso, a sufixação avaliativa.

Outro exemplo de forma aglutinada surge em (22c), cuja base é «Torre de Eita», cuja origem está ligada à existência de um ribeiro vulgarmente designado «Rio Eita» daí o sintagma toponímico «Torre d'Eita», como aliás durante muito tempo se escreveu o nome da freguesia ${ }^{1}$.

1. A informação relativa às origens do topónimo consta do projeto de lei n. ${ }^{\circ} 431 / \mathrm{VII}$ de elevação da povoação de Torredeita à categoria de vila, datado de 27 de novembro de 1987. Disponível em <http://debates.parlamento.pt/catalogo/r3/dar/s2a/ 07/03/014/1997-11-27/257?pgs=257-261\&org=PLC> . 


\section{Conclusões}

Embora os estudos de toponímia não sejam raros em Portugal, privilegiam a perspetiva etimológica, histórica e cultural. O presente trabalho pretendeu pôr o foco nos processos de carácter morfológico, sintático e semântico associados à construção dos topónimos, assentando numa perspetiva descritiva e maioritariamente linguística. Pretendeu-se, assim, ver de que forma a combinação de diferentes elementos linguísticos contribui para a denominação dos locais, ilustrando a necessidade de maior ou menor especificação, presente aquando do ato de designação toponímica.

Após a análise distintiva dos topónimos registados no corpus elaborado, partindo dos elementos simples «Castelo», «Castro» e «Torre», podemos dizer que eles apresentaram três tipos de estrutura: 1) elemento específico simples que é formado por um único morfema lexical; 2) elemento específico simples, acompanhado de flexão em género, em número ou grau ou de sufixos derivacionais; 3) elemento específico composto que apresenta mais de um elemento formador, resultante de expansão única ou plural, em torno dos termos primários, podendo esta estar anteposta e/ou posposta.

$\mathrm{O}$ terceiro tipo de estrutura assume-se como o mais produtivo na formação dos topónimos. Nas estruturas mórficas dos compostos, observamos que, nos sintagmas toponímicos, os elementos colocados à direita do termo genérico primário exercem uma função restritiva. Quando existem dois elementos num dado composto, estes podem ligar-se de forma mediata, através de preposições, ou imediatamente, sem o auxílio de conetivo. Ainda em relação às estruturas toponímicas compostas, o processo de adjetivação é um recurso linguístico importante, permitindo um acréscimo semântico na significação básica do elemento genérico.

O uso de termos secundários (derivados e compostos), em torno dos termos primários selecionados para a realização deste estudo ilustra como a toponímia tira partido dos múltiplos recursos que a língua coloca à disposição dos seus utilizadores. Essa variedade foi ilustrada pela multiplicidade de procedimentos formais convocados aquando do ato de denominação do lugar. De facto, considerando o corpus analisado, 53,2\% é constituído por sintagmas toponímicos de extensão variável, sobretudo com elementos conetivos entre os diferentes elementos do sintagma. Cerca de $25 \%$ do corpus é constituído por formas derivadas, com sufixos avaliativos, de número ou de género.

No corpus coligido, o termo «torre» revelou-se como o mais produtivo, quer enquanto topónimo simples, quer em unidades toponímicas poliléxicas como Torre Baixa (Penafiel, Porto), quer com elemento conetivo (e.g. Torre das Vargens, Portalegre), quer, ainda, em derivados (e.g. Torreões, Sabugal, Guarda) ou na flexão no plural (e.g. Torres, Trancoso, Guarda). 
As expansões em torno dos termos-base selecionados para a realização desta pesquisa, quer com a presença de elementos conetivos, quer sem a presença destes elementos ilustram a existência de nomes próprios de seres humanos (antropotopónimos), de santos (hagiotopónimos) e de particularidades decorrentes da natureza física dos locais (orografia, hidrografia, zonas de mata...), na concatenação toponímica. Uma análise semântica destes topónimos, recorrendo a princípios taxionómicos como os anteriormente referidos constitui um trabalho interessante e pertinente, a partir deste corpus ou de outro que venha a ser constituído. De facto, trabalhos futuros, no âmbito da toponímia, poderão contemplar a recolha de topónimos relacionados com a área lexical das construções militares, como forte ou atalaia, palavras que estão na base de topónimos como Atalaião (Portalegre), Monforte (Portalegre) ou Forte da Casa (Vila Franca de Xira, Lisboa).

Os constituintes que formam os topónimos compostos funcionam como uma só palavra, prevalecendo a unidade semântica do signo toponímico. De facto, cada um dos elementos constitutivos do topónimo perde a autonomia de significação em benefício de uma unidade semântica, isto é, de um único conceito, novo, global, resultando em formas lexicalizadas.

Embora os processos de formação de palavras estejam profundamente estudados, no caso dos topónimos, a sua descrição linguística carece de estudos mais exaustivos, que entendam o signo toponímico como uma realidade linguística e cultural, eivada de aspetos regionais que moldam a história e a identidade cultural de um determinado lugar. Assim, os topónimos transportam na sua estrutura sémica elementos da língua, da cultura e da época da sua formação. Não é, pois, de estranhar que em muitos locais, os castelos, os castros e as torres por onde andámos já não existam, permanecendo, apenas, no signo toponímico.

\section{REFERENCIAS BIBLIOGRAFICAS}

Azevedo Maria Luísa Seabra Marques de, 2005, Toponímia moçárabe no antigo condado conimbricense, Dissertação de Doutoramento, Coimbra, Faculdade de Letras da Universidade de Coimbra.

CAtalán Diego, 1989, «La toponimia y la re-romanización de Hispania. El ejemplo del diminutivo», Las lenguas circunvecinas del castellano, Madrid, Ariel, pp. 205-253.

Cunha Celso \& Cintra Lindley, 1994, Nova gramática do português contemporâneio, Lisboa, Sá da Costa.

Di Sciulo Anna Maria \& Williams Edwin, 1987, On the Definition of Word, Cambridge, Mass., The MIT Press. 
Machado José Pedro, 1993a, Dicionário Onomástico Etimológico da Língua Portuguesa, vol. 1, Lisboa, Livros Horizonte/Editorial Confluência.

Machado José Pedro, 1993b, Dicionário Onomástico Etimológico da Língua Portuguesa, vol. 2, Lisboa, Livros Horizonte/Editorial Confluência.

Machado José Pedro, 1993c, Dicionário Onomástico Etimológico da Língua Portuguesa, vol. 3, Lisboa, Livros Horizonte/Editorial Confluência.

Mateus Maria Helena Mira et al., 2003, Gramática da Língua Portuguesa, 5. edição revista e aumentada, Lisboa, Caminho.

Mateus Maria Helena Mira et al., 1990, Fonética, Fonologia e Morfologia do Português, Lisboa, Universidade Aberta.

Nascimento Maria Fernanda Bacelar do, 2013, «Processos de lexicalização», in E. Paiva Raposo et al. (eds), Gramática do Português, vol. I, Lisboa, Fundação Calouste Gulbenkian, pp. 215-246.

Rio-Torto Graça (éd), 2016, Gramática derivacional do português, Coimbra, Imprensa da Universidade de Coimbra.

Rostaing Charles, 1961, Les noms de lieux, Paris, Presses universitaires de France. Sandmann Antônio José, 1991, Competência Lexical, Curitiba, Editora da UFPR.

TRAPERo Maximiano, 2000, «La morfología derivativa como procedimiento de creación léxica: su especial importancia en la toponimia de Canarias. I: Diminutivos y aumentativos», in Estudios de dialectología dedicados a Manuel Alvar: con motivo del XL aniversario de El español hablado en Tenerife, La Laguna, Instituto de Estudios Canarios. Disponível em <http://hdl.handle.net/ 10553/3968> [último acesso a 18 de setembro de 2016].

Vasconcelos José Leite, 1995, Etnografia Portuguesa, vol. II [1936], Lisboa, Imprensa Nacional de Lisboa. 